\title{
Correction to: Prevalence of Paediatric Surgical Conditions in Eastern Uganda: A Cross-Sectional Study
}

\author{
Mary Margaret Ajiko ${ }^{1,2} \cdot$ Viking Weidman ${ }^{3} \cdot$ Pär Nordin $^{4} \cdot$ Andreas Wladis $^{5}$. \\ Jenny Löfgren ${ }^{1}$
}

Pär Nordin's and Andreas Wladis's affiliations have been corrected in the original article.

Publisher's Note Springer Nature remains neutral with regard to jurisdictional claims in published maps and institutional affiliations.

The original article can be found online at https://doi.org/10.1007/ s00268-021-06378-9.

Mary Margaret Ajiko strmaryajiko@gmail.com

1 Department of Molecular Medicine and Surgery, Karolinska Institute, Solna, Sweden

2 Soroti Regional Referral Hospital, Box 289, Soroti, Uganda

3 Uppsala University, Uppsala, Sweden

4 Department of Surgery and Perioperative Sciences, University of Umeå, Umeå, Sweden

5 Department of Biomedical and Clinical Sciences, Linköping University, Linköping, Sweden 